\title{
NMDA receptor antagonist MK-801 and nitric oxide synthase inhibitor L-NAME do not produce state-dependent learning in goldfish
}

\author{
XIAOJUAN XU, WILLIAM BOSHOVEN, and DENVER GUNN \\ Grand Valley State University, Allendale, Michigan
}

\begin{abstract}
Our previous studies have shown that MK-801, an NMDA antagonist, and L-NAME, an NO synthase inhibitor, produce anterograde amnesia at doses that do not impair performance processes that are necessary for learning to occur. Furthermore, MK-801 does not produce retrograde amnesia, whereas LNAME does. By using active avoidance conditioning as the learning paradigm and by using $2 \times 2$ factorial designs, in the present study we investigated whether MK-801 and L-NAME would produce state-dependent learning resulting in anterograde amnesia. Neither MK-801 nor L-NAME produced state-dependent learning. Thus, anterograde amnesia produced by MK-801 and L-NAME cannot be due to state-dependent learning. The present results, combined with our previous results, suggest that MK801 impairs learning, whereas L-NAME impairs memory consolidation and possibly learning.
\end{abstract}

Long-term potentiation (LTP), an activity-induced increase in the efficacy of neurotransmission, consists of an induction step and a maintenance step (Bliss \& Lynch, 1988). Investigations of synaptic transmission indicate that the induction of LTP may be mediated by postsynaptic receptors that are selectively sensitive to $N$-methyl-Daspartate (NMDA), and that the maintenance of LTP may be initiated by nitric oxide (NO), a retrograde messenger carrying signals backward from the postsynaptic to the presynaptic neurons. Administration of NMDA receptor antagonists to block NMDA receptor function has been shown to block induction but not maintenance of LTP (Gilbert \& Mack, 1990; Muller, Joly, \& Lynch, 1988), whereas a new series of studies has shown that blocking the synthesis of NO prevents the maintenance of LTP (E. P. Huang, 1997; Wu, Wang, Rowan, \& Anwyl, 1997).

LTP has been conceived to be a physiological correlate of learning and memory (Collingridge, Kehl, \& McLennon, 1983; Lynch et al., 1990). Behavioral investigations of the amnestic effects of NMDA receptor antagonists and NO synthase (NOS) inhibitors suggest that NMDA receptors and NO are involved in learning and memory. Administrations of NMDA receptor antagonists, such as aminophosphonopentanoic acid (AP5) and dizocilpine maleate (MK-801), produce anterograde amnesia in spatial learning (Heale \& Harley, 1990; Morris, Anderson, Lynch, \& Baudry, 1986; Shapiro \& Caramanos, 1990;

This work was supported in part by GVSU grant-in-aid and Trio Program (McNair Scholars). Correspondence should be addressed to X. Xu, Department of Psychology, Grand Valley State University, Allendale, MI 49401 (e-mail: xux@gvsu.edu).
Ward, Mason, \& Abraham, 1990), olfactory discrimination learning (Staubli, Thibault, DiLorenze, \& Lynch, 1989), and passive avoidance (Benvenga \& Spaulding, 1988; Danysz, Wroblewski, \& Costa, 1988; Parada-Turska \& Turski, 1990) and Pavlovian fear conditioning (Kim, Decola, Landeira-Fernandez, \& Fanselow, 1991; Miserendino, Sananes, Melia, \& Davis, 1990; Sanger \& Joly, 1991; Xu \& Davis, 1992; Xu, Klinger, \& Davis, 1995). Administrations of NOS inhibitors, such as $\mathrm{L}-\mathrm{N}^{\mathrm{G}}$ monomethylarginine (L-MeArg) and $N$-nitro-L-arginine (L-NOARG), have been shown to produce anterograde and retrograde amnesia in inhibitory avoidance tasks in rats (Bernabeu, de Stein, Fin, Izquierdo, \& Medina, 1995; A. Huang \& Lee, 1995), but only anterograde amnesia in chicks (Holscher \& Rose, 1993). Administration of nitroL-arginine methyl-ester (L-NAME), an NOS inhibitor, has also been reported to produce anterograde amnesia in the water maze task (Chapman, Atkins, Allen, Haley, \& Steinmetz, 1992; Estall, Grant, \& Cicala, 1993) and the radial arm maze task in rats (Yamada et al., 1995). However, infusion of L-NOARG into the olfactory bulb at doses that effectively inhibit NO synthase activity does not impair olfactory learning in mice (Brennan \& Kishimoto, 1993).

Using active avoidance conditioning as the learning paradigm, in our previous studies we have compared the amnestic effects of NOS inhibitors, including L-NAME, with the amnestic effects of NMDA receptor antagonist MK-801 in goldfish. We have also investigated the effects of L-NAME and MK-801 on the expression of previously learned avoidance responses and addressed the issue of whether amnesia produced by L-NAME and MK-801 could be due to impairments of perception or motor coor- 
dination or motivational processes that are necessary for learning to occur. The results indicate that administration of MK-801 or L-NAME before training produces significant anterograde amnesia at doses that do not impair performance processes necessary for learning to occur. Furthermore, administration of MK-801 immediately following training does not produce retrograde amnesia, whereas administration of L-NAME immediately following training does ( $\mathrm{Xu} \&$ Boshoven, 1997; Xu, Boshoven, Lombardo, \& Spranger, 1998).

In most behavioral studies and in our previous experiments to detect anterograde amnestic effects of MK-801 and L-NAME in active avoidance conditioning, the drugs have been present during the training sessions but not the test session. Learning that occurs under the influence of a drug may not transfer to the undrugged condition and is referred to as state-dependent learning or retrieval. The phenomenon reflects a failure to retrieve learned information in the absence of the drug (Spear, 1973). Thus the anterograde amnesia produced by MK-801 and L-NAME could reflect state-dependent learning as opposed to a disruption of learning of avoidance responses. To investigate this possibility, in the present study we examined whether retention in the testing session would vary with the presence or absence of the drugs, using $2 \times 2$ factorial designs.

\section{METHOD}

\section{Subjects and Experimental Drugs}

Goldfish (Carassius auratus L.) $8-10 \mathrm{~cm}$ in length and obtained from Ozark Fisheries (Stoutland, MO) were kept in large tanks for several weeks prior to experimentation. During the experiments, the fish were kept in individual compartments of partitioned tanks at $18^{\circ}-22^{\circ} \mathrm{C}$ on a $12: 12$-h light:dark cycle (0700-1900 light). The experiments were conducted during the light cycle. $(+)$-Dizocilpine maleate (MK-801) and $N^{\mathrm{G}}$-nitro-L-arginine methyl ester hydrochloride (L-NAME) (Research Biochemicals Inc., Natick, MA) were dissolved in $10 \mu \mathrm{l}$ of water and administered intracranially with the aid of a 30 gauge needle and a $100-\mu$ l Hamilton syringe.

\section{Apparatus}

The fish were trained and tested individually in four identical fish shuttleboxes connected to a Smart Control (Med Associates, Albans, VT). The fish shuttlebox consisted of a water-filled tank $(41 \mathrm{~cm}$ long $\times 20.5 \mathrm{~cm}$ wide $\times 10.5 \mathrm{~cm}$ deep) divided by an opaque barrier $(20.5 \mathrm{~cm}$ wide $\times 10.5 \mathrm{~cm}$ deep $)$ into two equal compartments. A rectangular opening $(8 \mathrm{~cm}$ wide $\times 2.5 \mathrm{~cm}$ deep $)$ in the barrier allowed the fish to swim freely from one side of the tank to the other. The crossing movement of the fish was monitored by four infrared light beams and their corresponding detectors, located on the long sides of the tank. There was a light $(75 \mathrm{~W}, 125 \mathrm{~V}, \mathrm{dc})$ at each end of the tank, and there were two stainless steel electrode plates $(18 \mathrm{~cm}$ long $\times 19.5 \mathrm{~cm}$ wide) at the top and bottom of each compartment.

\section{Active Avoidance Paradigm}

The fish were placed in the shuttleboxes for $5 \mathrm{~min}$, and then a trial began with the onset of the light on the side of the fish's location. After the light was on for $20 \mathrm{sec}$, a repetitive mild electrical shock $(1 \mathrm{~V} / \mathrm{cm}$ $\mathrm{dc}$, pulsed $200 \mathrm{msec}$ on and $800 \mathrm{msec}$ off) was administered for $20 \mathrm{sec}$ through the water by means of electrodes. At the end of $40 \mathrm{sec}$ or upon a crossing response by the fish during the $40 \mathrm{sec}$, the trial ended. After an intertrial interval (ITI) ranging from $25-55 \mathrm{sec}$, another trial began.
The fish initially swam through the opening only after receiving several shocks. The crossing response following the onset of both light signal and electrical shock in order to escape the electrical bodyshock is here defined as an escape response. During the training sessions, the fish gradually learned to swim from the lighted end to the dark end to avoid an electric bodyshock. The crossing response following the onset of the light signal but before the onset of electrical shock to avoid the electrical bodyshock is here defined as an avoidance response. A few days later, the fish were tested. A training session consisted of 20 trials, and the testing session consisted of 10 trials. The measurements were the number of avoidances, escapes, and crossings during the ITI. All experiments were fully automated through the Smart Control and a single 486 computer that programmed the stimuli and monitored and recorded behavior of fish. Fish that showed an ITI crossing of $25 \%$ or less during training sessions were retained in the study. The percentage of avoidance responses was used as an indicator of learning.

\section{Procedure}

In Experiment 1, we investigated whether MK-801 produced state-dependent learning. We divided naive fish into four groups. They were trained semiweekly on Experimental Days 1, 4, and 8 and were tested on Experimental Day 11. The four groups of fish received either $3.2 \mu \mathrm{g}$ of $\mathrm{MK}-801$ or water before training or testing or both.

In Experiment 2, we investigated whether L-NAME produced state-dependent learning. We divided naive fish into four groups. They were trained semiweekly on Experimental Days 1, 4, and 8 and were tested on Experimental Day 11. These four groups of fish received either $100 \mu \mathrm{g}$ of $\mathrm{L}-\mathrm{NAME}$ or water before training or testing or both. The doses of $3.2 \mu \mathrm{g}$ of MK- 801 and $100 \mu \mathrm{g}$ of L-NAME were used because they produced anterograde amnesia similarly to each other and had not impaired performance processes in our previous studies.

\section{RESULTS}

Fish that received water injections both before training and testing in Experiments 1 and 2 did not differ and were combined as one water-water control group. The water-water control group was used as the control group in both Experiments 1 and 2. A two-way analysis of variance (ANOVA) of the testing data of Experiment 1 indicated a significant effect of pretraining MK-801 $[F(1,37)=31.28, p<.001]$, but not of pretesting MK$801[F(1,37)=0.315, p>.05]$, nor was there an interaction between pretraining and pretesting MK-801 $[F(1,37)=0.185, p>.05]$. (See Figure 1 A.) Further independent Student's $t$ tests revealed that the fish that received MK-801 prior to training sessions showed significantly fewer avoidance responses in the testing session. More importantly, reinstating MK- 801 prior to the testing session did not increase avoidance responses; and giving MK-801 only before the testing session did not impair expression of learned avoidance responses. Furthermore, learning curves showed that fish that received water prior to training sessions showed steady increases in avoidance responses over sessions, whereas fish that received MK-801 prior to training sessions did not show such increases in avoidance responses over sessions (Figure 1B). Thus, MK-801 did not produce state-dependent learning of active avoidance conditioning. 


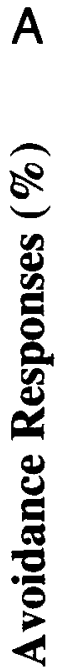

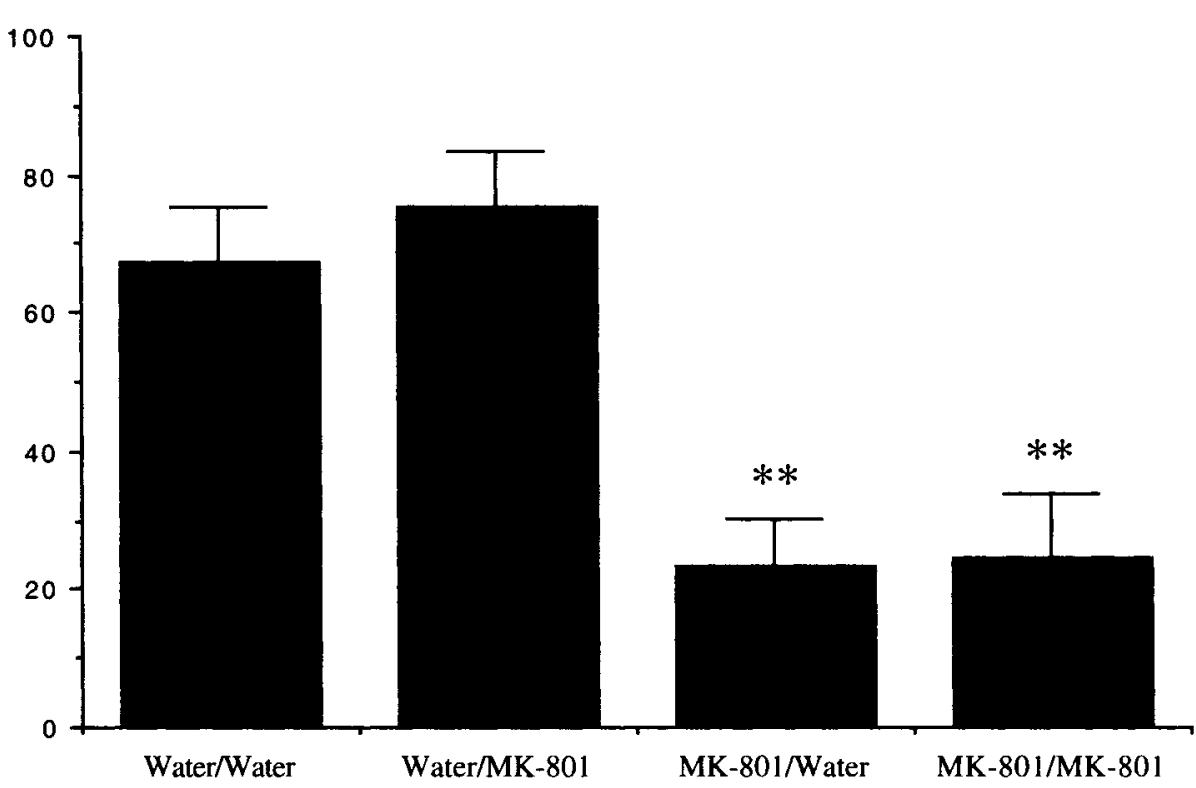

Groups

B

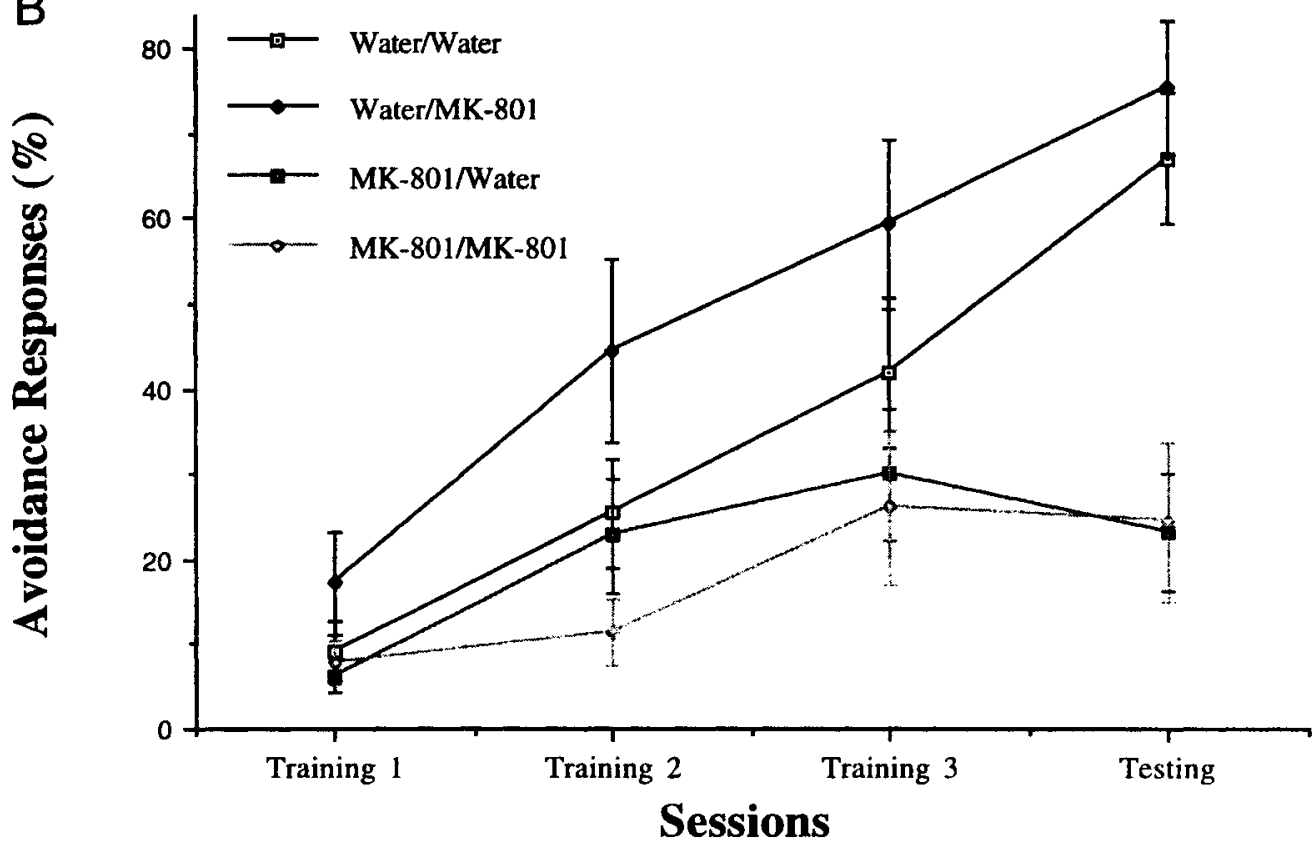

Figure 1. (A) State-dependency effects of MK-801. Each bar represents the mean percentage of avoidance responses ( $\pm S E$ ) for each group ( $n=9$, except that the water/water control group contained 14 fish) during the testing session. (B) Learning curves for each group over four sessions. Each point represents the mean percentage of avoidance responses $( \pm S E)$. water/water group received water injections both before training and testing. Water/MK-801 group received water injections before training and $M K-801$ before testing. MK-801/water group received MK-801 injections before training and a water injection before testing. MK-801/MK-801 group received MK-801 injections both before training and testing. ** $p<.01$ (comparison with the control group). 
Another two-way ANOVA of the testing data of Experiment 2 indicated a significant effect of pretraining L-NAME $[F(1,37)=10.132, p<.01]$, but not of pretesting L-NAME $[F(1,37)=0.141, p>.05]$; nor was there an interaction between pretraining and pretesting $\mathrm{L}$ NAME $[F(1,37)=0.067, p>.05]$. (See Figure 2A.) Further independent Student's $t$ tests revealed that fish that received L-NAME prior to the training sessions showed significantly fewer avoidance responses in the testing session. More importantly, reinstating L-NAME prior to the testing session did not increase avoidance responses; and giving L-NAME only before the testing session did not impair expression of learned avoidance responses. Furthermore, learning curves showed that fish that received water prior to the training sessions showed steady increases in avoidance responses over sessions, whereas fish that received L-NAME prior to the training sessions did not show such increases in avoidance responses over sessions (Figure 2B). Therefore, L-NAME did not produce state-dependent learning of active avoidance conditioning either.

\section{DISCUSSION}

The present results confirmed the previous finding that MK-801 and L-NAME produced anterograde amnesia in active avoidance conditioning at the dose that did not impair performance processes that are necessary for learning to occur (Xu \& Boshoven, 1997; Xu et al., 1998). Furthermore, MK-801 and L-NAME did not produce state-dependent learning of active avoidance conditioning.

MK-801 has been shown to have stimulus effects at very low systemic doses in mammals (Sanger \& Zivkovic, 1989 ). Thus, the anterograde amnesia produced by MK801 could result from impairment of learning processes, state-dependent learning, impairment of performance processes that are necessary for learning to occur, or impairment of memory consolidation (i.e., the processes completed following the learning experience) if drug effects last throughout learning and memory consolidation. Our previous studies have shown that MK-801 produces anterograde amnesia at doses that do not impair performance processes that are necessary for learning to occur; and that MK-801 does not produce retrograde amnesia, suggesting that MK-801 does not impair memory consolidation (Xu \& Boshoven, 1997; Xu et al., 1998). The present study confirms the previous finding that MK801 produces anterograde amnesia at the dose that does not impair perception of lights or motivation of avoiding shocks or execution of avoidance responses. Furthermore, the present study shows that MK-801 does not produce state-dependent learning. Therefore, the anterograde amnesia produced by MK-801 reflects impairment of learning processes by MK-801.

Our previous study showed that NOS inhibitors produced retrograde amnesia, suggesting that NOS inhibitors impair memory consolidation. However, larger doses of intracranial injections of NOS inhibitors were needed to produce retrograde than to produce anterograde amnesia (Xu et al., 1998). Thus, the anterograde amnesia effects of L-NAME could indicate that NOS inhibitors impair both memory consolidation and learning; that NOS inhibitors impair memory consolidation and produce state-dependent learning; or that NOS inhibitors impair memory consolidation and performance processes that are necessary for learning to occur. However, our previous studies have shown that L-NAME produced anterograde amnesia at doses that do not impair performance processes, which is also confirmed by the present study. Furthermore, the present study shows that anterograde amnesia effects of L-NAME cannot be attributed to a state-dependent generalization decrement. Therefore, the anterograde amnesia produced by L-NAME reflects impairment of memory consolidation and possibly learning.

In the mammalian brain, NMDA receptor antagonists and NOS inhibitors respectively block the induction and expression of LTP in the hippocampus (Gilbert \& Mack, 1990; Haley, Wilcox, \& Chapman, 1992). Therefore, it has been suggested that NMDA receptor antagonists and NOS inhibitors produce anterograde and retrograde amnesia through their interaction with the mammalian hippocampus (Bernabeu et al., 1995; Morris et al., 1986). In teleosts, no agreement exists about the structures that could be homologous to the hippocampus (Northcutt, 1995). However, studies have suggested that the goldfish telencephalon plays an important role in learning and memory. Telencephalon ablation impairs avoidance learning (Hainsworth, Overmier, \& Snowden, 1967) and spatial learning in goldfish (Salas, Rodriguez, Vargas, Duran, \& Torres, 1996). A recent binding study has detected NMDA-sensitive components most densely in the telencephalon of the goldfish brain (Barnes \& Henley, 1994). The presence of NOS in the goldfish telencephalon has also been detected (Bruning, Katzbach, \& Mayer, 1995). Thus, it is possible that MK-801 and L-NAME produced anterograde and retrograde amnesia by exerting effects in the goldfish telencephalon.

The role of NMDA receptors in learning and memory has been examined mainly in mammalian preparations (Danysz et al., 1988; Kim et al., 1991; Morris et al., 1986; Staubli et al., 1989), and the role of NO has also been studied mainly in mammals (Bernabeu et al., 1995; Chapman et al., 1992; Yamada et al., 1995). Our studies (Xu et al., 1998; Xu \& Davis, 1992; Xu et al., 1995) show that in goldfish, NMDA receptor antagonists and NOS inhibitors produce amnestic effects similar to those observed in mammals. Furthermore, in mammals, NMDA receptors are most highly concentrated in the telencephalon, and particularly in the hippocampus (Monaghan \& Cotman, 1985). In goldfish, the binding study also showed NMDA sensitive components most densely in the telencephalon (Barnes \& Henley, 1994). The presence of NOS in the telencephalon has been detected in both mammals and goldfish (Bruning et al., 1995; Vincent \& Kimura, 1992). The similarity of amnestic effects of NMDA receptor antagonists and NOS inhibitors in fish and mammals and the similarity of locations of NMDA receptors and NOS 

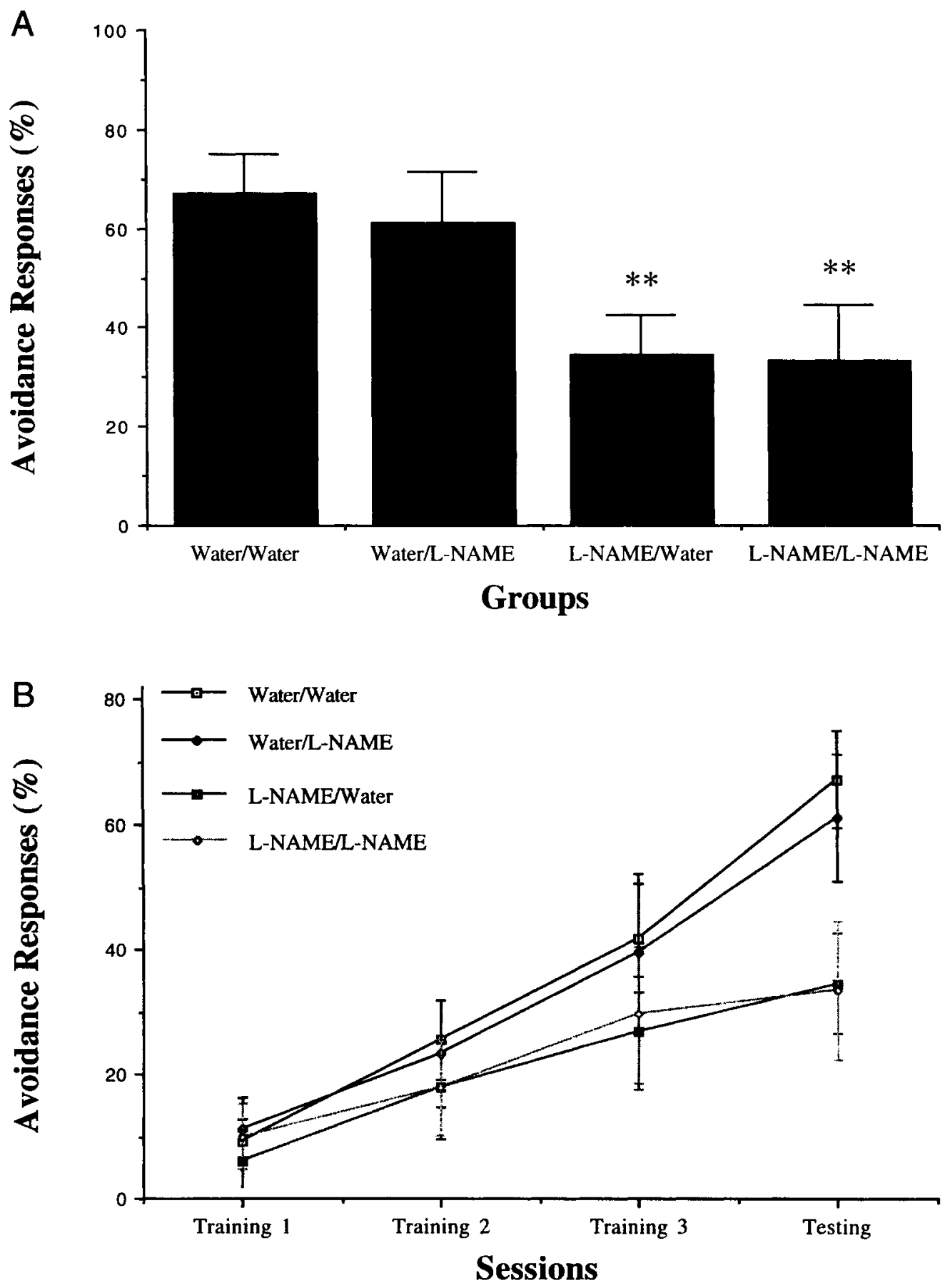

Figure 2. (A) State-dependency effects of L-NAME. Each bar represents the mean percentage of avoidance responses ( $\pm S E$ ) for each group ( $n=9$, except that the water/water control group contained 14 fish) during the testing session. (B) Learning curves for each group over four sessions. Each point represents the mean percentage of avoidance responses $( \pm S E$ ). Water/water group received water injections before both training and testing. Water/L-NAME group received water injections before training and L-NAME before testing. L-NAME/water group received L-NAME injections before training and a water injection before testing. L-NAME/L-NAME group received L-NAME injections before both training and testing. ** $p<.01$ (comparison with the control group). 
in fish and mammals suggest that the roles of NMDA receptors and NO in learning and memory may be similar for all vertebrates.

\section{REFERENCES}

Barnes, J. M., \& Henley, J. M. (1994). Quantitative analysis of the distribution of glutamatergic ligand binding sites in goldfish brain. Brain Research, 637, 323-327.

Benvenga, M. J., \& Spaulding, T. C. (1988). Amnestic effect of the novel anticonvulsant MK-801. Pharmacology, Biochemistry \& Behavior, 30, 205-207.

Bernabeu, R., de Stein, M. L., Fin, C., Izquierdo, I., \& Medina, J. H. (1995). Role of hippocampal NO in the acquisition of inhibitory avoidance learning. NeuroReport, 6, 1498-1500.

Bliss, T. V. P., \& LyNCH, M. A. (1988). Long-term potentiation of synaptic transmission in the hippocampus: Properties and mechanisms. In P. W. Landfield \& S. A. Deadwyler (Eds.), Long-term potentiation from biophysics to behavior (pp. 3-72). New York: Alan R. Liss.

Brennan, P. A., \& Kishimoto, J. (1993). Local inhibition of nitric oxide synthase activity in the accessory olfactory bulb does not prevent the formation of an olfactory memory in mice. Brain Research 619, 306-312.

Bruning, G., Katzbach, R., \& Mayer, B. (1995). Histochemical and immunocytochemical localization of nitric oxide synthase in the central nervous system of the goldfish, Carassius auratus. Journal of Comparative Neurology, 358, 353-382.

Chapman, P. F., Atkins, C. M., Allen, M. T., Haley, J. E., \& SteinMETZ, J. E. (1992). Inhibition of nitric oxide synthesis impairs two different forms of learning. NeuroReport, 3, 567-570.

Collingridge, G. L., KeHL, S. J., \& MCLENNON, H. (1983). Excitatory amino acids in synaptic transmission in the Schaffer colaterolcommissural pathway of the rat hippocampus. Journal of Physiology, 334, 33-46.

DANYSZ, W., WROBLEWSKI, J. T., \& COSTA, Z. (1988). Learning impairment in rats by $\mathrm{N}$-methyl-D-aspartate receptor antagonists. Neuropharmacologv, 27, 653-656.

Estall, L. B., Grant, S. J., \& Cicala, G. A. (1993). Inhibition of nitric oxide (NO) production selectively impairs learning and memory in the rat. Pharmacology, Biochemistry \& Behavior, 46, 959-962.

Gilbert, M. E., \& MACK, C. M. (1990). The NMDA antagonist, MK801 , suppresses long-term potentiation, kindling, and kindling-induced potentiation in the perforant path of the unanesthetized rat. Brain Research, 519, 89-96.

Hainsworth, F. R., Overmier, J. B., \& Snowden, C. T. (1967). Specific and permanent deficits in instrumental avoidance responding following forebrain ablation in the goldfish. Journal of Comparative \& Phvsiological Psychology, 63, $111-116$

Haley, J. E., Wilcox, G. L., \& Chapman, P. E. (1992). The role of nitric oxide in hippocampal long-term potentiation. Neuron, 8, 211 . 216.

Heale, N., \& HARLEY, C. (1990). MK-801 and AP5 impair acquisition, but not retention, of the Morris milk maze. Pharmacology, Biochemistry \& Behavior, 36, 145-149.

HolsCher, C., \& Rose, S. R. R. (1993). Inhibiting synthesis of the putative retrograde messenger nitric oxide results in amnesia in a passive avoidance task in the chick. Brain Research, 619, 189-194.

HUANG, A., \& LEE, E. H. Y. ( 1995). Role of hippocampal nitric oxide in memory retention in rats. Pharmacology, Biochemistry \& Behavior, 3, 327-332.

HUANG, E. P. (1997). Synaptic plasticity: A role for nitric oxide in LTP. Current Biologv, 7, R141-R143.

Kim, J. J., Decola, J. P., Landeira-Fernandez, J., \& Fanselow, M. S. (1991). $N$-methyl-D-aspartate receptor antagonist APV blocks acquisition but not expression of fear conditioning. Behavioral Neuroscience, 105, 126-133.

Lynch, M. A., Errington, M. L., Clements, M. P., Bliss, T. V. P., Redini-Del Negro, C., \& Laroche, S. (1990). Increases in glutamate release and phosphoinositide metabolism associated with long- term potentiation and classical conditioning. Progress in Brain Research, 83, 251-256.

Miserendino, M. J. D., Sananes, C. B., Melia, K. R., \& Davis, M (1990). Blocking of acquisition but not expression of conditioned fear-potentiated startle by NMDA antagonists in the amygdala. $\mathrm{Na}$ ture, 345, 716-718.

Monaghan, D. T., \& Cotman, C. W. (1985). Distribution of $N$-methylD-aspartate-sensitive $\mathrm{L}-\left[{ }^{3} \mathrm{H}\right]$ glutamate binding sites in rat brain. Journal of Neuroscience, 5, 2909-2919.

Morris, R. G. M., Anderson, E., LynCh, G. S., \& Baudry, M. (1986) Selective impairment of learning and blockade of long-term potentiation by an $N$-methyl-D-aspartate receptor antagonist, AP5. Nature, 319, 774-776.

Muller, D., Joly, M., \& LynCH, G. (1988). Contributions of quisqualate and NMDA receptors to the induction and expression of LTP. Science, 242, 1694-1697.

NoRTHCUTT, R. G. (1995). The forebrain of Gnathostomos: In search of a morphotype. Brain, Behavior \& Evolution, 46, 275-318.

Parada-Turska, J., \& TURSKI, W. A. (1990). Excitatory amino acid antagonists and memory: Effect of drugs acting at $N$-methyl-D-aspartate receptors in learning and memory tasks. Neuropharmacology, 29 $1111-1116$.

Salas, C., Rodriguez, F., Vargas, J. P., Duran, E., \& Torres, B (1996). Spatial learning and memory deficits after telencephalic ablation in goldfish trained in place and turn maze procedures. Behavioral Neuroscience, 110, 965-980.

SANGER, D. J., \& JolY, D. (1991). Effects of NMDA receptor antagonists and sigma ligands on the acquisition of conditioned fear in mice Psychopharmacology, 104, 27-34.

SANGER, D. J., \& ZivKovic, B. (1989). The discriminative stimulus ef fects of MK-801: Generalization to other $N$-methyl-D-aspartate receptor antagonists. Journal of Psychopharmacology, 3, 198-204.

ShapiRo, M. L., \& CARAMANOS, Z. (1990). NMDA antagonist MK-801 impairs acquisition but not performance of spatial working and reference memory. Psychobiology, 18, 231-243.

SPEAR, N. E. (1973). Retrieval of memory in animals. Psychological Review, 80, 163-194.

Staubli, U., Thibault, O., Dilorenze, M., \& Lynch, G. (1989). Antagonism of NMDA receptors impairs acquisition but not retention of olfactory memory. Behavioral Neuroscience, 103, 54-60.

VINCENT, S. R., \& KimURA, H. (1992). Histochemical mapping of nitric oxide synthase in the rat brain. Neuroscience, 46, 755-784.

Ward, L., Mason, S. E., \& Abraham, W. C. (1990). Effects of NMDA antagonists CPP and MK-801 on radial arm maze performance in rats. Pharmacology, Biochemistry \& Behavior, 35, 785-790.

WU, J., WANG, Y., RowaN, M. J., \& ANWYL, R. (1997). Evidence for involvement of the neuronal isoform of nitric oxide synthase during in duction of long-term potentiation and long-term depression in the rat dentate gyrus in vitro. Neuroscience, 78, 393-398.

Xu, X., \& Boshoven, W. (1997). Anterograde amnestic effects of NMDA receptor antagonist MK-80I and nitric oxide inhibitor $\mathrm{L}$ NAME [Abstract]. Amino Acids, 13, 68.

Xu, X., Boshoven, W., Lombardo, B., \& Spranger, J. (1998). Comparison of the amnestic effects of NMDA receptor antagonist MK801 and nitric oxide synthase inhibitors: L-NAME and L-NOARG in goldfish. Behavioral Neuroscience, 112, 892-899.

XU, X.. \& DAVIS, R. E. (1992). NMDA receptor antagonist MK-801 impairs learning but not memory fixation or expression of classical fear conditioning in goldfish. Behavioral Neuroscience, 106, 307-314

Xu, X., Klinger, P., \& Davis, R. (1995). Comparative anterograde amnestic and anticonvulsant effects of two types of NMDA receptor antagonists: MK-801 and HA-966. Psychopharmacology, 117, 333 339.

Yamada, K., Noda, Y., Nakayama, S., Komori, Y., Sugihara, H., Hasegawa, T., \& Nabeshima, T. (1995). Role of nitric oxide in learning and memory and in monoamine metabolism in the rat brain. British Journal of Pharmacology, 115, 852-858.

(Manuscript received July 20, 1998. revision accepted for publication November 13, 1998.) 